\title{
Correlation between vertical components and skeletal Class II malocclusion in ethnic Javanese
}

This article was published in the following Dove Press journal:

Clinical, Cosmetic and Investigational Dentistry

\author{
I Gusti Aju Wahju Ardani' \\ Ira Willyanti² \\ Ida B Narmada' \\ 'Orthodontic Department, Faculty \\ of Dental Medicine, Universitas \\ Airlangga, Surabaya, Indonesia; \\ ${ }^{2}$ Faculty of Dental Medicine, \\ Universitas Airlangga, Surabaya, \\ Indonesia
}

\begin{abstract}
Introduction: The dentoskeletal morphology of Class II malocclusion has been analyzed in several cephalometric investigations. It is crucially important to understand the vertical components in orthodontic treatment. Defining the facial type of an individual is an essential key to obtain an accurate orthodontic diagnosis.
\end{abstract}

Aim: The aim of this study was to understand the correlation of vertical components in Class II skeletal malocclusion.

Materials and methods: This is a observational descriptive study. This study used lateral cephalograms of Class II skeletal malocclusion from Universitas Airlangga Dental Hospital, between April 2015 and 2016. Cephalometric analysis was performed using digital software by a single examiner. This analysis measured gonial $(\mathrm{Go})$, upper gonial $\left(\mathrm{Go}_{1}\right)$, lower gonial $\left(\mathrm{Go}_{2}\right)$, Yaxis-SN angle, the length of anterior face height, and posterior face height. The correlation between each variable was analyzed using the Pearson correlation test $(P<0.01)$.

Results: There was a correlation between vertical components and Class II skeletal malocclusion. Conclusion: Vertical components were correlated with Class II skeletal malocclusion. The greater ANB angle will be followed by greater $\mathrm{Go}_{2}$, which worsens the condition of Class II skeletal malocclusion.

Keywords: AFH, ANB, Class II skeletal malocclusion, $\mathrm{Go}_{1}, \mathrm{Go}_{2}$, $\mathrm{PFH}$, Yaxis, Yaxis-SN

\section{Introduction}

The dentoskeletal morphology of Class II malocclusion has been analyzed in several cephalometric investigations. Defining the facial type of an individual is an essential key to obtain an accurate orthodontic diagnosis, and the lateral cephalogram is presented in literatures as a relevant resource for this purpose. ${ }^{1,2}$ Class II division 1 (Class II/1) malocclusion represents the most common skeletal discrepancy, which orthodontists see in daily practice. ${ }^{3}$ The understanding of this morphology is a key element in planning dentofacial orthopedic treatment for this type of malocclusion. Clinically widely accepted term of "skeletal Class II" does not specify whether the mandible is retruded in relation to the maxilla, or the maxilla is protruded in relation to the mandible. ${ }^{4,5}$

The Class II/1 incisal relationship was found in association with a range of vertical skeletal patterns. Some studies reported an increase in lower facial height, whereas other studies reported that the lower facial height was significantly reduced. Class II division 2 (Class II/2) malocclusion is usually associated with an increase in posterior face height $(\mathrm{PFH})$, a decrease in mandibular plane angle, a decrease in anterior face height $(\mathrm{AFH})$, and a more horizontal growth vector. ${ }^{1}$
Ardani

Orthodontic Department, Faculty of Dental Medicine, Campus A Universitas Airlangga JI Prof Dr Moestopo, No 47, Surabaya 60132, East Java, Indonesia

Tel +62315030255

Fax +62315020256

Email wahju_ardani@fkg.unair.ac.id 
Skeletal class II malocclusion may be caused by the maxillary prognation of maxillary depth or the angle formed between the Frankfurt plane and the $\mathrm{N}-\mathrm{A}$ line, by mandibular retrograde, ie, reduced facial depth or angle formed between the Frankfurt plane and the facial plane (N-Pog), or by the combination of both conditions. As the causes of skeletal Class II malocclusion are varied, the treatment will also differ depending on the underlying cause. ${ }^{6}$

The difficulty in controlling vertical dimension during orthodontic treatment is a long-recognized fact. Therefore, it is crucial to thoroughly understand the vertical face height (VFH) in orthodontic treatment. Vertical dimension, generally speaking, includes AFH and PFH. ${ }^{7}$

\section{Materials and methods \\ Sample}

The preliminary research consisted of 465 Javanese (DeutroMelayu) adult population who were seeking orthodontic treatment at the Universitas Airlangga Dental Hospital from April 2015 to 2016. From the total sample, there were 202 patients with skeletal Class I malocclusion (ANB 1-3), 171 patients with skeletal Class II malocclusion (ANB $>4$ ), and 92 patients with skeletal Class III malocclusion (ANB $<0$ ). There were only 106 skeletal Class II malocclusion patients who meet our eligibility criteria, with the age range of 15-35 years, of whom 21 patients were males and 85 patients were females. The study was performed in accordance with the Declaration of Helsinki, and human ethics approval was attained from the Faculty of Dental Medicine, Universitas Airlangga, Health Research Ethical Clearance Commission No 271/HRECC.FODM/X/2018. All patients provided a written informed consent to review their medical records as per the policy of Faculty of Dental Medicine, Universitas Airlangga. The inclusion criteria of sample selection were ANB $>4.5$, male or female patient with skeletal Class II malocclusion who had never done any orthodontic treatment before full permanent dentition.

Lateral cephalogram was taken in natural head position with subject closing their teeth in centric occlusion and lips in relax position. Cephalometric analysis was performed using the digital software OrthoVision (Ewoosoft Co., Ltd, Gyeonggi-do, South Korea) by a single examiner. The analysis started with determining the landmark anatomies shown in Figure 1, such as

1. SNA: angle formed from the points sella (S), nasion $(\mathrm{N})$, and $\mathrm{A}$. The range of normal values is $80^{\circ}-84^{\circ}$.

2. SNB: angle formed from the points $\mathrm{S}, \mathrm{N}$, and $\mathrm{B}$. The range of normal values is $78^{\circ}-82^{\circ}$.

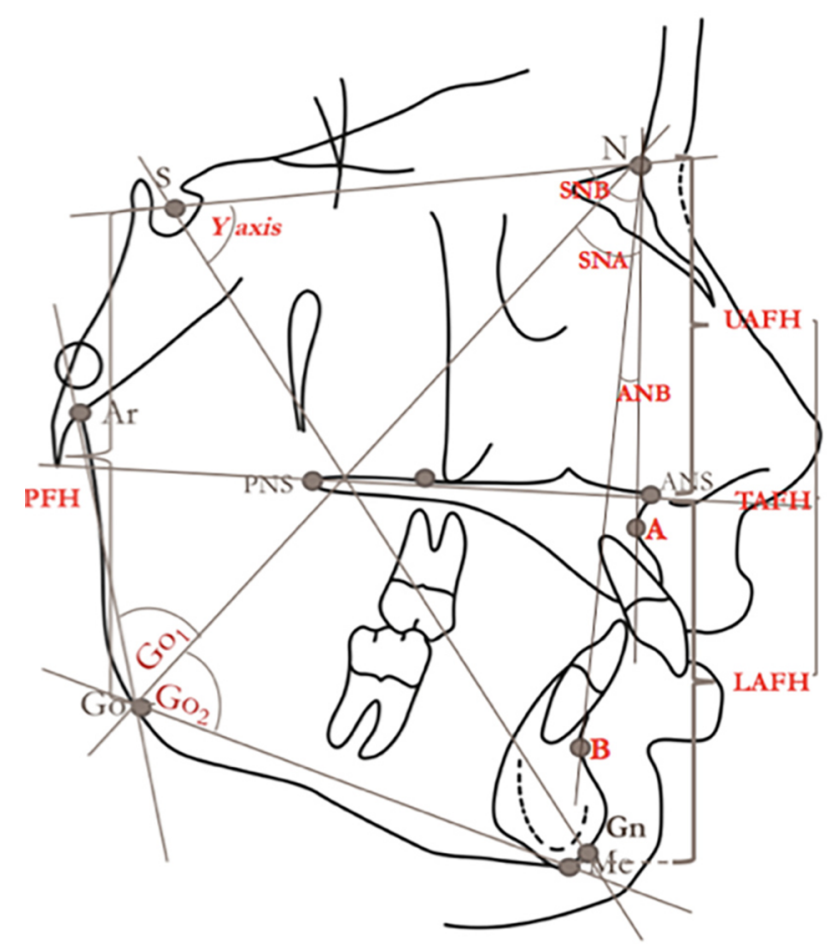

Figure I Anatomical landmarks used in this research.

Abbreviations: $\mathrm{Go}_{1}$, upper gonial; $\mathrm{Go}_{2}$, lower gonial; $\mathrm{AFH}$, anterior face height; UAFH, upper anterior face height; LAFH, lower anterior face height; TAFH, total anterior face height; $\mathrm{PFH}$, posterior face height.

3. ANB: angle between SBA and SNB. The range of normal values is $0^{\circ}-4^{\circ}$.

4. $\mathrm{Go}_{1}$ : angle formed from the points articulare (Ar), Go, and $\mathrm{N}$. The range of normal values is $52^{\circ}-55^{\circ}$.

5. $\mathrm{Go}_{2}$ : angle formed from the points $\mathrm{N}, \mathrm{Go}$, and menton (Me). The range of normal values is $70^{\circ}-75^{\circ}$.

6. Upper AFH (UAFH): a line measured from points $\mathrm{N}$ to anterior nasal spine (ANS).

7. Lower AFH (LAFH): a line measured from points ANS to Me.

8. Total AFH (TAFH): a line measured from points $\mathrm{N}$ to Me. This distance indicates a long or short AFH.

9. PFH: distance from the $\mathrm{S}-\mathrm{Go}$ points. This distance indicates a long or short PFH.

10. Yaxis: angle formed from the Frankfort horizontal (FH) plane with the S-gnathion (S-Gn) line is used to determine the direction of mandibular growth. The average value is $59.4^{\circ}$.

11. Yaxis-SN: angle formed from $\mathrm{SN}$ line with $\mathrm{S}-\mathrm{Gn}$ line is used to determine the direction of mandibular growth. The average value is $66^{\circ}$.

\section{Statistical analysis}

The mean and SD of the measurement counted were determined using SPSS 17.0 (SPSS Inc., Chicago, IL, USA) for 
Windows OS. The data distribution was calculated by means of Kolmogorov-Smirnov $(P>0.05)$, while the correlation between each variable was analyzed using the Pearson correlation test.

\section{Results}

The mean and SD of each parameters are shown in Table 1. The correlation test in this study used Pearson correlation with statistical significant if $P<0.01$. Table 2 shows there was no correlation between SNA and $\mathrm{Go}_{1}$ and LAFH, whereas a negative correlation was found between SNA and $\mathrm{Go}_{2}$, UAFH, AFH, Yaxis, and Yaxis-SN. There was a positive correlation between SNA and PFH. While there was no correlation between $\mathrm{SNB}$ and $\mathrm{Go}_{1}$, a positive correlation was found in SNB to PFH and a negative correlation was found in $\mathrm{SNB}$ to $\mathrm{Go}_{2}$, UAFH, LAFH, AFH, Yaxis, and Yaxis-SN. There was no correlation in the relationship between ANB and $\mathrm{Go}_{1}$, UAFH, LAFH, and AFH. A positive correlation was found between ANB and Yaxis and Yaxis-SN, whereas negative correlation was found between $\mathrm{Go}_{2}$ and $\mathrm{PFH}$.

Table I Descriptive data of measurement variable

\begin{tabular}{|l|l|l|l|}
\hline Variable & Minimum & Maximum & Mean \pm SD \\
\hline SNA $\left(^{\circ}\right)$ & 73.44 & 97.65 & $82.43 \pm 3.94$ \\
SNB $\left(^{\circ}\right)$ & 60.51 & 87.50 & $75.56 \pm 4.18$ \\
ANB $\left(^{\circ}\right)$ & 4.54 & 13.58 & $6.86 \pm 1.73$ \\
$\mathrm{Go}_{1}\left({ }^{\circ}\right)$ & 37.74 & 59.42 & $46.97 \pm 4.75$ \\
$\mathrm{Go}_{2}\left({ }^{\circ}\right)$ & 55.78 & 95.00 & $79.29 \pm 6.55$ \\
UAFH $(\mathrm{mm})$ & 36.46 & 62.41 & $51.22 \pm 4.47$ \\
LAFH $(\mathrm{mm})$ & 54.25 & 81.14 & $66.51 \pm 5.55$ \\
AFH $(\mathrm{mm})$ & 94.16 & 138.73 & $117.72 \pm 8.18$ \\
PFH $(\mathrm{mm})$ & 55.10 & 95.16 & $73.32 \pm 7.29$ \\
Yaxis $\left({ }^{\circ}\right)$ & 57.93 & 84.48 & $70.99 \pm 5.05$ \\
Yaxis-SN $\left({ }^{\circ}\right)$ & 62.82 & 91.85 & $73.29 \pm 4.59$ \\
\hline
\end{tabular}

There was a positive correlation between $\mathrm{Go}_{1}$ and $\mathrm{Go}_{2}$, whereas a negative correlation was found between $\mathrm{Go}_{1}$ and UAFH, LAFH, AFH, and PFH. Go ${ }_{1}$ did not correlate with Yaxis and Yaxis-SN. Go Gas $_{2}$ positively correlated with LAFH, AFH, Yaxis, and Yaxis-SN and was negatively correlated with $\mathrm{PFH}$. There was no correlation between $\mathrm{Go}_{2}$ and UAFH. The UAFH was positively correlated with LAFH, $\mathrm{AFH}, \mathrm{PFH}$, and Yaxis-SN, and there was no correlation between UAFH and Yaxis. LAFH was positively correlated with AFH, PFH, Yaxis, and Yaxis-SN. AFH was positively correlated with PFH, Yaxis, and Yaxis-SN. PFH did not correlate with Yaxis but negatively correlated with Yaxis-SN. Yaxis was positively correlated with Yaxis-SN.

\section{Discussion}

This study discusses the relationship between SNA, SNB, ANB, $\mathrm{Go}_{1}, \mathrm{Go}_{2}, \mathrm{UAFH}, \mathrm{LAFH}, \mathrm{AFH}, \mathrm{PFH}$, Yaxis, and Yaxis$\mathrm{SN}$ in the patients with skeletal Class II malocclusions at Universitas Airlangga Dental Hospital. First, we discuss the relationship between SNA, SNB, and ANB with $\mathrm{Go}_{1}, \mathrm{Go}_{2}$, AFH, PFH, and Yaxis-SN. Ricketts determined the mandibular growth arch as the guide to predict the mandibular growth. Gonial angle position moves posteriorly on this growth arch, a distance that equaled almost one half of the total increase in mandibular growth. This study used Yaxis and Yaxis-SN, because the FH plane can be used to analyze the lower dentofacial abnormalities and using only one reference plane can provide less valid data due to the variations in the $\mathrm{FH} .{ }^{8}$ According to the results of this study, Yaxis-SN has more correlation because the growth of the lower face is not separated from the growth of the upper face, and according to a previous study, SN field is more stable. ${ }^{9}$ Yaxis-SN can be used to measure vertical growth associated with anterior

Table 2 Pearson correlation table

\begin{tabular}{|c|c|c|c|c|c|c|c|c|}
\hline $\begin{array}{l}\text { Pearson } \\
(r / p)\end{array}$ & Go, & $\mathbf{G o}_{2}$ & UAFH & LAFH & AFH & PFH & Yaxis & Yaxis-SN \\
\hline SNA & $0.006 / 0.948$ & $-0.318 * / 0.001$ & $-0.299 * / 0.002$ & $-0.132 / 0.177$ & $-0.253 * / 0.009$ & $0.239 * / 0.014$ & $-0.303 * / 0.002$ & $-0.745 * / 0$ \\
\hline SNB & $0.010 / 0.917$ & $-0.453 * / 0$ & $-0.240 * / 0.013$ & $-0.196 * / 0.044$ & $-0.264 * / 0.006$ & $0.319 * / 0.001$ & $-0.410 * / 0$ & $-0.856 * / 0$ \\
\hline ANB & $-0.008 / 0.932$ & $0.377 * / 0$ & $-0.113 / 0.25 \mid$ & $0.176 / 0.07 \mid$ & $0.058 / 0.554$ & $-0.237 * / 0.015$ & $0.311 * / 0.001$ & $0.376 * / 0$ \\
\hline $\mathrm{Go}_{1}$ & - & $0.206 * / 0.034$ & $-0.267 * / 0.006$ & $-0.255 * / 0.008$ & $-0.319 * / 0.001$ & $-0.303 * / 0.002$ & $-0.069 / 0.483$ & $-0.133 / 0.173$ \\
\hline $\mathrm{Go}_{2}$ & $0.206 * / 0.034$ & - & $0.017 / 0.861$ & $0.477 * / 0$ & $0.333 * / 0$ & $-0.398^{*} / 0$ & $0.510 * / 0$ & $0.682 * / 0$ \\
\hline UAFH & $-0.267 * / 0.0 .006$ & $0.017 / 0.861$ & - & $0.325 * / 0.001$ & $0.767 * / 0$ & $0.468 * / 0$ & $-0.049 / 0.616$ & $0.248 * / 0.010$ \\
\hline LAFH & $-0.255 * / 0.008$ & $0.477 * / 0$ & $0.325 * / 0.001$ & - & $0.856 * / 0$ & $0.390 * / 0$ & $0.370 * / 0$ & $0.369 * / 0$ \\
\hline $\mathrm{AFH}$ & $-0.319 * / 0.001$ & $0.333 * / 0$ & $0.767 * / 0$ & $0.856 * / 0$ & - & $0.521 * / 0$ & $0.224 * / 0.021$ & $0.386 * / 0$ \\
\hline PFH & $-0.303 * / 0.002$ & $-0.398 * / 0$ & $0.468 * / 0$ & $0.390 * / 0$ & $0.521 * / 0$ & - & $-0.130 / 0.186$ & $-0.309 * / 0.001$ \\
\hline Yaxis & $-0.069 / 0.483$ & $0.510 * / 0$ & $-0.049 / 0.616$ & $0.370 * / 0$ & $0.224 * / 0.021$ & $-0.130 / 0.186$ & - & $0.580 * / 0$ \\
\hline Yaxis-SN & $-0.133 / 0.173$ & $0.682 * / 0$ & $0.248 * / 0.010$ & $0.369 * / 0$ & $0.386 * / 0$ & $-0.309 * / 0.001$ & $0.580 * / 0$ & - \\
\hline
\end{tabular}

Note: *Correlation is significant at the 0.01 level (two tailed).

Abbreviations: $\mathrm{Go}_{1}$, upper gonial; $\mathrm{Go}_{2}$, lower gonial; AFH, anterior face height; UAFH, upper anterior face height; LAFH, lower anterior face height; TAFH, total anterior face height; PFH, posterior face height. 
and posterior changes and may determine vertical inferior anterior growth of the mandible. ${ }^{10}$

In this study, SNA and SNB are negatively correlated with $\mathrm{Go}_{2}$. The mean value of SNA (82.43) is normal, whereas the mean of SNB (75.56) is smaller than normal; it shows that most of the cases are retrognathic mandible. There are many variations in the anteroposterior skeletal relationships in Class II division 2 malocclusion but mostly are retrognathic mandible. ${ }^{2}$ The SNB $(-0.453)$ correlation to $\mathrm{Go}_{2}$ is stronger than that of SNA $(-0.318)$. This indicates that patients with small SNB will have greater $\mathrm{Go}_{2}$ angle, which mean that the patients tend to have a downward-backward mandibular rotation. Gonial angle size tends to be inversely related to and significantly correlated with mandibular body length and the size of angles SNA and ANB. ${ }^{8}$ Increase in gonial angle is accompanied by an increase in mandibular length. Björk described an increasing curvature of the mandibular base and noted that this increase was accompanied by a reduction in the size of the gonial angle. This reduction, in turn, was accompanied by vertical condylar growth, whereas both the gonial angle and sagittal growth increased. ${ }^{11}$ Mandibular length was not all related to gonial angle size. The mandibular body length was significantly related and inversely proportional to the gonial angle size. That is, individuals with a small gonial angle tended to have a larger mandibular body length and the SNA angle and ANB angle were also larger in cases with a smaller gonial angle. ${ }^{8}$

SNA and SNB angles are negatively correlated with UAFH, LAFH, AFH, Yaxis, and Yaxis-SN. The smaller the angle SNB means the length of UAFH increases and the length of LAFH increases too; this will result in the increase in the length of AFH. The SNA angle significantly correlated with Yaxis-Sn $(-0.745)$ meaning that the larger the SNA, the lower the Yaxis-SN value. There is a very significant correlation between ANB and Yaxis-SN (-0.856); the smaller the SNB, then the mandible tends to rotate downward-backward. The mean value of ANB (6.86) greater than normal is positively correlated with $\mathrm{Go}_{2}$, Yaxis, and Yaxis-SN meaning that the greater the ANB angle the mandible is likely to rotate downward-backward. There is no correlation between ANB and UAFH, LAFH, and AFH. The ANB angle is negatively correlated with $\mathrm{PFH}$, indicating that the greater the angle of ANB the PFH reduced. With respect to the posterior height, it weakly associated with the actual mandibular length and maxilla length and moderately and positively correlated with the anteroposterior position of the mandible and maxilla. Schudy depicted the vertical and anteroposterior growth as opposing forces, which sounds reasonable with AFH being regarded as vertical height in the extreme case of long or short face type. In relative normal overbite case, some studies showed that the vertical growth of PFH is consistent with anteroposterior growth. ${ }^{?}$

The mean value of $\mathrm{Go}_{1}$ angle (46.97) is smaller than normal with a positive correlation with $\mathrm{Go}_{2}$; the smaller the $\mathrm{Go}_{1}$ angle, the smaller $\mathrm{Go}_{2}$ angle too. In this study, the average value of $\mathrm{Go}_{2}$ (79.29) is greater than normal probably due to downward-backward rotation of the mandible. The angle of $\mathrm{Go}_{1}$ is negatively correlated with UAFH, LAFH, AFH, PFH, and Yaxis-SN but not correlated with Yaxis. This shows that the smaller the value of $\mathrm{Go}_{1}$, the larger the values of UAFH, LAFH, and AFH, causing downward-backward rotation of the mandible.

Figure 2 shows a patient with skeletal Class II malocclusion with ANB angle (12.93), $\mathrm{Go}_{2}$ (92.9), and Yaxis-SN (91.85). This patient showed a great ANB angle and along with the rotation of the mandible. The mean angle value of $\mathrm{Go}_{2}$ (79.29) is greater than normal negatively correlated with $\mathrm{PFH}$. The $\mathrm{Go}_{2}$ angle is positively correlated with LAFH, $\mathrm{AFH}$, Yaxis, and Yaxis-SN. The correlation between $\mathrm{Go}_{2}$ and Yaxis-SN is very significant (0.682), proving that $\mathrm{Go}_{2}$ strongly reflects on the mandibular rotation. This means that the larger the angle of $\mathrm{Go}_{2}$ then the greater the length of LAFH and AFH and the lower the length of PFH, causing downward-backward mandibular rotation. The steeper the

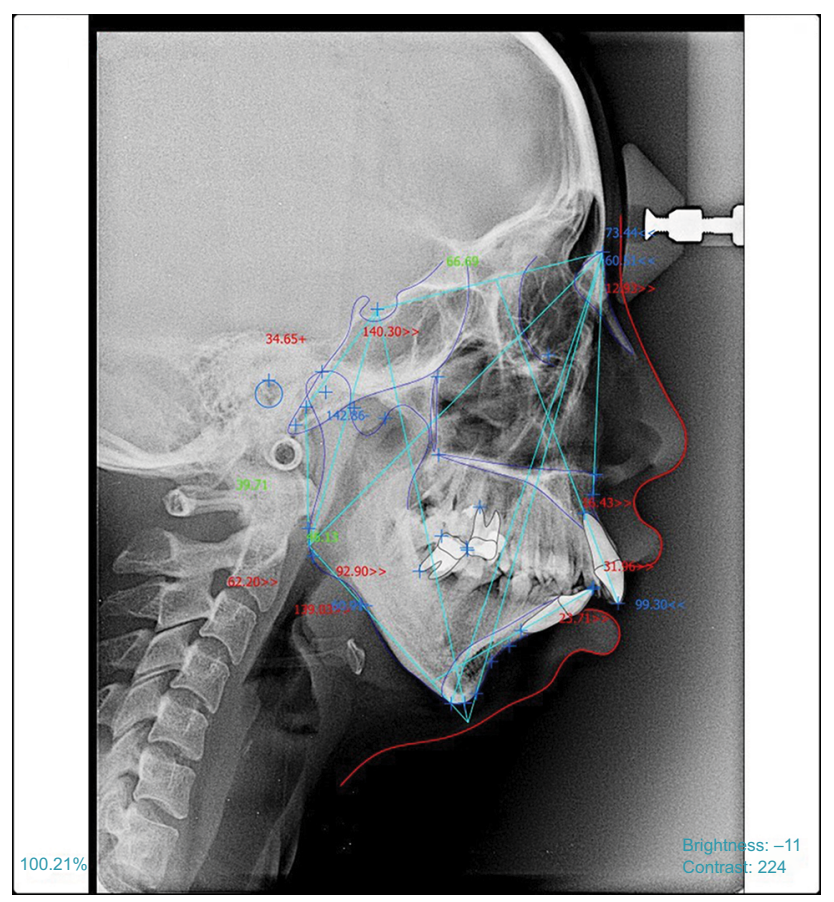

Figure 2 Class II skeletal malocclusion with great value of ANB, $\mathrm{Go}_{2}$, and Yaxis-SN. 
mandibular plane anteriorly inclines, the greater the $\mathrm{AFH}$ becomes or vice versa. ${ }^{12}$ There is no correlation between $\mathrm{Go}_{2}$ angle and UAFH. The high angle ramus is shorter, whereas the low angle ramus tends to be longer. ${ }^{13}$

Vertical dimensional control is a difficult task on orthodontic treatment. It is important to understand VFH in orthodontic treatment. ${ }^{11}$ Vertical dimensions include AFH and PFH. The ratio of UAFH/LAFH $(<0.8)$ was obtained from the mean of UAFH (51.22) and LAFH (66.51), meaning that LAFH is longer. According to statistical results data in this study, the UAFH values were positively correlated with LAFH, AFH, PFH, and Yaxis-SN. This shows that the smaller the UAFH value then LAFH, AFH, PFH, and Yaxis$\mathrm{SN}$ will decrease. UAFH is significantly correlated with $\mathrm{AFH}$ (0.767). UAFH is not correlated with Yaxis, whereas LAFH is positively correlated with $\mathrm{AFH}, \mathrm{PFH}$, Yaxis, and Yaxis-SN. The greater the $\mathrm{LAFH}$ value then the greater the AFH, PFH, Yaxis, and Yaxis-SN. LAFH is significantly correlated with AFH (0.856).

From the mean of AFH (117.72) and PFH (73.32), the ratio of $\mathrm{AFH} / \mathrm{PFH}(62.2 \%)$ was obtained showing that, in this study, patients with skeletal Class II malocclusion tend to have a balanced PFH and AFH. AFH values are positively correlated with PFH, Yaxis, and Yaxis-SN. This indicates that the longer the anterior face, the greater the length of posterior face and the greater the angles of Yaxis and Yaxis-SN, resulting in a downward-backward rotation of the mandible. According to Björk, forward mandibular rotation occurs when $\mathrm{PFH}$ overdevelops relative to $\mathrm{AFH}$; however, in many literatures, more attention was focused on the $\mathrm{AFH}$ and lower AFH has been confirmed as having a strong influence on the formation of vertical facial disproportions. ${ }^{14}$ In contrast, some accepted terminologies used in describing vertical morphology, such as long face and short face and dolichofacial and brachyfacial, are mainly based on AFH. ${ }^{15-17}$ In normal cases, long PFH is always followed by long AFH and vice versa. Graber ${ }^{18}$ found that if the gonial angle is acute, mandibular growth is more vertical and directed more anteriorly. The value of PFH is negatively correlated with Yaxis-SN, and the greater the PFH the Yaxis-SN value will increase indicating the forward rotation of the mandible. Yaxis angle itself is positively correlated with Yaxis-SN. The Yaxis-SN angle is a measurement of mainly vertical growth very sensible to anterior and posterior changes, which collaborates in defining the vertical of anterior inferior growth of the mandible, detecting its degree of opening. ${ }^{19}$

Cases with normal overbite, forward rotation of the mandible cannot be simply regarded as the growth result of relatively long PFH together with relatively short AFH. In other words, the reason for mandibular forward rotation is not because of increase in PFH together with a decrease in AFH but different increased dimensions of it. ${ }^{7}$ These study results showed that it is the underdevelopment or overdevelopment of PFH instead of AFH that plays a key role in mandibular rotation. This agrees with Björk who stated that, under ideal circumstances, the fulcrum point for anterior or forward mandibular growth rotation is located at the incisors. Therefore, as the result of forward rotation, both the AFH and PFH increase. ${ }^{14}$

Thus, a face with a low angle, normally accompanied by a long ramus and a wide frontal region (wide bizygomatic and bigonial), can easily produce an illusion of a short face, although the anterior lower face height could be normal. This also explains why many faces with a low angle are taken for granted to be assumed as a short face, whereas a wide face and a square profile are responsible for making faces appear short.

Many literatures were more focused in the AFH and LAFH values as it has been confirmed to have a strong influence on the formation of vertical facial disproportions. Reducing facial height can be done by the extrusion of molars to compensate for backward rotation by increasing the forward mandibular rotation with minimal effect on anterior vertical facial dimensions. This may be applied during treating adolescent patient with skeletal Class II caused by small size of the ramus and body of the mandible. This relationship often results in a decreased $\mathrm{PFH}$, a steeper mandibular plane angle, an increased ANB angle between SNA and SNB, a normal SNA angle with a decreased SNB angle, an increased angle of convexity, and an increased overjet.

\section{Conclusion}

Patients with Class II skeletal malocclusion in Javanese population do not always have a short anterior face. From the results of this study, the greater the ANB angle then the greater the value of $\mathrm{Go}_{2}$ and this can be caused by the downward-backward rotation of the mandible. This mandibular rotation is evidenced by the increasing value of Yaxis-SN. As the value of $\mathrm{Go}_{2}$ increases, the AFH value will also increase. This proves that Class II in Javanese population has a high anterior face. The increased AFH will aggravate Class II skeletal malocclusion. Orthodontic treatment in Class II skeletal malocclusion with high AFH is more difficult.

\section{Acknowledgments}

This work has not been published previously and is not under consideration by another journal and is the work of the 
author(s). Research grant is funded by Universitas Airlangga no 373/UN3.14/LT/2018.

\section{Disclosure}

The authors report no conflicts of interest in this work.

\section{References}

1. Al-Khateeb EA, Al-Khateeb SN. Anteroposterior and vertical components of class II division 1 and division 2 malocclusion. Angle Orthod. 2009;79(5):859-866.

2. Isik F, Nalbantgil D, Sayinsu K, Arun T. A comparative study of cephalometric and arch width characteristics of class II division 1 and division 2 malocclusions. Eur J Orthod. 2006;28(2):179-183.

3. PachoriY, Navlani M, GaurT, Bhatnagar S. Treatment of skeletal class II division 1 malocclusion with mandibular deficiency using myofunctional appliances in growing individuals. J Indian Soc Pedod Prev Dent. 2012;30(1):56.

4. Sidlauskas A, Svalkauskiene V, Sidlauskas M. Assessment of skeletal and dental pattern of class II division 1 malocclusion with relevance to clinical practice. Stomatologija. 2006;8(1):3-8.

5. Al-Azzawi AM, Sahib WW, Al-Khafaji TJ. Assessment of skeletal and dental pattern of the mandible of class II division 1 malocclusion [A comparative cephalometric study]. kufa J Nurs Sci. 2011;1:17-48.

6. Hoffelder LB, de Lima EM, Martinelli FL, Bolognese AM. Soft-tissue changes during facial growth in skeletal class II individuals. Am J Orthod Dentofacial Orthop. 2007;131(4):490-495.

7. Wang MF, Otsuka T, Akimoto S, Sato S. Vertical facial height and its correlation with facial width and depth. Int J Stomatol Occlusion Med. 2013;6(4):120-129.
8. de Rossi M, Stuani MBS, da SLAB. Cephalometric evaluation of vertical and anteroposterior changes associated with the use of bonded rapid maxillary expansion appliance. Dental Press J Orthod. 2010;15:62-70.

9. Ardani I, Sanjaya ML, Sjamsudin J. Cephalometric characteristic of skeletal class II malocclusion in Javanese population at Universitas Airlangga Dental Hospital. Contemp Clin Dent. 2018;9(Suppl 2):S342.

10. Steiner C. Cephalometries in clinical practice. Angle Orthod. 1959;29: 8-29.

11. Kim YH. Overbite depth indicator with particular reference to anterior open-bite. Am J Orthod. 1974;65(6):586-611.

12. Obaidi HA. Variation of facial heights among the class I, II and III dentoskeletal relationships (Cephalometric study). Al-Rafidain Dent J. 2006:98-105.

13. Yassir YA. Ramus Height and its relationship with skeletal and dental measurements. J Oral Dent Res. 2013;1(1):4-8.

14. Björk A. Prediction of mandibular growth rotation. Am J Orthod. 1969;55(6):585-599.

15. Bishara SE, Saunders WB. Textbook of Orthodontics. Collingwood, ON: Saunders Book Company; 2001.

16. Bishara SE, Jakobsen JR. Longitudinal changes in three normal facial types. Am J Orthod. 1985;88(6):466-502.

17. Schudy FF. Vertical growth versus anteroposterior growth as related to function and treatment. Angle Orthod. 1964;34:75-93.

18. Graber LW. Chin cup therapy for mandibular prognathism. Am JOrthod. 1977;72(1):23-41.

19. Paranhos LR, Benedicto EN, Nunes MF, Kairalla SA, Siqueira DF, Torres FC. Correlation of different cephalometric measurements to define facial type. Int J Orthod Milwaukee. 2012;23(1):31.
Clinical, Cosmetic and Investigational Dentistry

\section{Publish your work in this journal}

Clinical, Cosmetic and Investigational Dentistry is an international, peer-reviewed, open access, online journal focusing on the latest clinical and experimental research in dentistry with specific emphasis on cosmetic interventions. Innovative developments in dental materials, techniques and devices that improve outcomes and patient satisfac-

\section{Dovepress}

tion and preference will be highlighted. The manuscript management system is completely online and includes a very quick and fair peerreview system, which is all easy to use. Visit http://www.dovepress. com/testimonials.php to read real quotes from published authors. 